\title{
Multiple medication use in older patients in post- acute transitional care: a prospective cohort study
}

This article was published in the following Dove Press journal:

Clinical Interventions in Aging

2 September 2014

Number of times this article has been viewed

\author{
Maureen Runganga ${ }^{1,2}$ \\ Nancye M Peel ${ }^{2}$ \\ Ruth E Hubbard ${ }^{2,3}$ \\ 'The Prince Charles Hospital, \\ Chermside, QLD, Australia; ${ }^{2}$ Centre \\ for Research in Geriatric Medicine, \\ The University of Queensland School \\ of Medicine, QLD, Australia; ${ }^{3}$ Princess \\ Alexandra Hospital, Woolloongabba, \\ QLD, Australia
}

Background: Older adults with a range of comorbidities are often prescribed multiple medications, which may impact on their function and cognition and increase the potential for drug interactions and adverse events.

Aims: This study investigated the extent of polypharmacy and potentially inappropriate medications in patients receiving post-discharge transitional home care and explored the associations of polypharmacy with patient characteristics, functional outcomes, and frailty.

Methods: A prospective observational study was conducted of 351 patients discharged home from hospital with support from six Transition Care Program (TCP) sites in two states of Australia. A comprehensive geriatric assessment was conducted at TCP admission and discharge using the interRAI Home Care assessment tool, with frailty measured using an index of 57 accumulated deficits. Medications from hospital discharge summaries were coded using the World Health Organization Anatomical Therapeutic Chemical Classification System.

Results: Polypharmacy (5-9 drugs) was observed in 46.7\% and hyperpolypharmacy ( $\geq 10$ drugs) in $39.2 \%$ of patients. Increasing numbers of medications were associated with greater number of comorbid conditions, a higher prevalence of diabetes mellitus, coronary heart disease, chronic obstructive pulmonary disease, dizziness, and dyspnea and increased frailty. At discharge from the program, the non-polypharmacy group ( $<5$ drugs) had improved outcomes in Activities of Daily Living, Instrumental Activities of Daily Living and fewer falls, which was mediated because of lower levels of frailty. The commonest drugs were analgesics (56.8\%) and antiulcer drugs $(52.7 \%)$. The commonest potentially inappropriate medications were tertiary tricyclic antidepressants.

Conclusion: Polypharmacy is common in older patients discharged from hospital. It is associated with frailty, falls, and poor functional outcomes. Efforts should be made to encourage regular medication reviews and rationalization of medications as part of discharge planning. Whether careful deprescribing improves outcomes in frail patients should be the focus of randomized trials.

Keywords: polypharmacy, older people, post-acute care, functional outcomes

\section{Introduction}

Background

Older adults with a range of comorbidities are often prescribed multiple medications, some of which may impact on their function and cognition, and many have a potential for drug interactions. ${ }^{1}$ Studies showing evidence of benefit from pharmacotherapy have mostly been conducted in younger patients, and it is unclear how this translates to frail older patients. These patients are often excluded from drug trials; yet they are the largest consumers of medications. ${ }^{1}$ Several studies have found current use of five or more drugs in well over a quarter of older community dwelling adults, ${ }^{2-4}$ with higher prevalence in frail older populations and in hospitalized patients. ${ }^{5,6}$
Correspondence: Nancye M Peel Centre for Research in Geriatric Medicine, Level 2, Building 33, Princess Alexandra Hospital, Woolloongabba, QLD 4102, Australia

Tel +6I 73 I 767402

Fax +61731766945

Email n.peel@uq.edu.au 
The assessment of frailty using various methods, including the Frailty Index, is being incorporated in recent studies of older adults and provides an insight into their accumulated deficits and reduced reserve. ${ }^{7,8}$ The increased number of comorbidities requiring medications makes these patients prone to polypharmacy, yet their frailty status, together with the pharmacokinetic and pharmacodynamic changes that occur with aging, places them at risk of adverse events. The risks of polypharmacy include non-adherence, adverse drug reactions, drug-drug interactions, falls, fractures, poor nutrition, and mortality, ${ }^{9-14}$ as well as increased exposure to potentially inappropriate medications (PIMs). ${ }^{5,15}$ However, few studies have reported on the association of polypharmacy with functional outcomes in older patients.

\section{Aims}

The aims of the study were to

1. Explore the extent of polypharmacy in a cohort of older patients discharged from hospital to a home care program;

2. Assess the relationship between polypharmacy and patient characteristics, functional outcomes, and frailty; and

3. Describe the prevalence of the most common medications in this cohort, with particular emphasis on PIMs.

\section{Methods}

\section{Study design, setting, and participants}

A prospective observational cohort study of older persons discharged from hospital to a community-based Transition Care Program was conducted at six sites in two Australian states, Queensland and South Australia. The Transition Care Program (TCP) is designed to facilitate transitions from hospital to home for older people (aged 70 years and over or 50 years and over for the indigenous population), offering those with high care needs additional support during convalescence. ${ }^{16}$ The program is therapy focused, providing a package of services which includes home help and personal care, physiotherapy and occupational therapy, nursing care, and case management over a maximum period of 12 weeks (average 7 weeks) post-discharge from hospital. ${ }^{16}$ The provision of primary medical care to a Transition Care recipient is undertaken by their general practitioner. ${ }^{16}$

Consecutive patients entering the TCP during the period from November 2009 to September 2010, who gave informed consent to participate, were eligible for the study. Recruitment details for the study, originally designed to examine the functional recovery trajectories of patients with high care needs, have previously been published. ${ }^{17}$ Ethics approval was given by the University of Queensland Human Research Ethics Committee (HREC) as well as HRECs responsible for governance at each of the TCP sites.

\section{Data collection}

A comprehensive geriatric assessment using the interRAI Home Care instrument was conducted at TCP admission and discharge. The interRAI instruments comprise a suite of assessment tools to support assessment and care planning of persons with chronic illness, frailty, and disability across care settings,${ }^{18}$ with substantial reliability on core items in common. ${ }^{19}$ The interRAI Home Care assessment collects data on multiple domains including sociodemographics, medical conditions, medications, physical and mental function, nutrition, and symptoms and syndromes such as mood, behavior, and continence. A number of scales embedded in the interRAI instruments combine single items belonging to a domain, such as activities of daily living (ADL), instrumental ADL (IADL), and cognition, which can be used to describe the presence and extent of deficits in that domain. ${ }^{17,20,21}$ Trained assessors gathered data from multiple sources including from the patient, carers, medical and allied health staff, and hospital records. Medications from hospital discharge summaries were coded by pharmacy students using the World Health Organization Anatomical Therapeutic Chemical (ATC) Classification System and reviewed by a pharmacist and a geriatrician.

\section{Measures}

\section{Medication exposure}

There is no universally accepted definition of polypharmacy in the literature. Some studies define it as use of five or more medications. ${ }^{2-411}$ This has been supported in a recent study investigating polypharmacy cutoff points and risks of adverse outcome. ${ }^{22}$ Moreover, recent studies have defined the use of ten or more medications as excessive polypharmacy ${ }^{10,23}$ or hyperpolypharmacy. ${ }^{24}$ Inclusion of over-the-counter medications and medications not consumed on a regular basis is also variable. In our study, polypharmacy status was categorized into three groups non-polypharmacy ( $0-4$ drugs), polypharmacy (5-9 drugs), and hyperpolypharmacy ( $\geq 10$ drugs) - based on regular medications. Drugs, vitamins, and mineral supplements administered on a regular basis through any recognized drug-delivery method were included in the analysis. Supplements without ATC codes, such as cranberry juice and primrose oil, were excluded. 
The American Geriatrics Society 2012 Beers Criteria was used to identify PIMs with a recommendation to avoid, regardless of patients' comorbidities. We included as PIMs those medications where the recommendation to avoid was strong and the quality of evidence was classified as moderate or high, also taking into account exposure to drugs above recommended maximum daily dose. ${ }^{25}$ Table S1 lists the PIMs meeting these criteria.

\section{Frailty}

The frailty index (FI) was calculated using a well described methodology, ${ }^{26}$ based on accumulated health deficits such as symptoms, signs, disabilities, and diseases measured in the interRAI Home Care assessment. Disability in ADL and IADL, impairments in general cognition and mobility, number of comorbidities, incontinence, and depressed mood were included as deficits. For each patient, deficits were added and divided by the total counted, here 57 , to calculate an individual index score. Polypharmacy was excluded from the deficit count. The higher the score, the greater the number of deficits, and the more likely the patient is to be frail. In community-dwelling older people, 0.25 has been proposed as the cutoff between "fit" and "frail," with scores of $>0.40$ associated with dependence on others for activities of daily living. ${ }^{27}$

\section{Analysis}

To describe characteristics across polypharmacy groups, comparison of means (analysis of variance) or medians (Kruskal-Wallis test) for continuous variables was used, depending on distribution of the data. For categorical variables, chi-square or Fisher's exact test (where cell numbers are less than five) was performed. An exploratory analysis using logistic regression models tested the association between polypharmacy, frailty status, and functional outcomes. For the purpose of interpreting odds ratios, FI was multiplied by 10 so that the per-unit change was $0.1{ }^{8}$ Patients with missing data were excluded from the relevant analysis, and percentages were reported as proportions of patients with available data. Significance level was set at $P$-value of $<0.05$. The SPSS IBM version 22 was used for analysis.

\section{Results}

Of the $351 \mathrm{TCP}$ clients enrolled in the study, four cases had missing medication data. The remaining 347 cases were included in the analysis. The mean age (standard deviation [SD]) was $78.9( \pm 8.8)$ years, and $65.7 \%$ were females. The majority of patients discharged to the TCP needed ongoing support after hospitalization for orthopedic conditions (50.7\%), including fractures $(37.5 \%)$, medical conditions resulting in deconditioning (23.6\%), and stroke (14.6\%). The median length of stay in the TCP was 54 days (interquartile range 37-73 days).

The number of regular medications taken ranged from 0 to 24 , with a mean (SD) of $8.5( \pm 3.6)$. For "as needed" pro re nata $(\mathrm{PRN})$ medications, the mean $(\mathrm{SD})$ was $0.8( \pm 1.1)$. Only $14.1 \%$ of patients took $<5$ regular medications (nonpolypharmacy). Polypharmacy (5-9 drugs) was observed in $46.7 \%$ and hyperpolypharmacy ( $\geq 10$ drugs) in $39.2 \%$. The majority in the hyperpolypharmacy group ( $\mathrm{n}=131 ; 96.3 \%)$ were taking between 10 and 15 regular medications, with five taking more than 15 regular medications.

Table 1 shows the characteristics of patients according to polypharmacy categories at admission to the TCP. Patients with polypharmacy and hyperpolypharmacy had more comorbidities than the non-polypharmacy group and were more likely to have diabetes mellitus, coronary heart disease, chronic obstructive pulmonary disease (COPD), or depression. They were also more likely to have symptoms of pain, dizziness, and dyspnea. There was no significant association between polypharmacy categories and stroke, congestive heart disease, Parkinson's disease, or cancer. Considering frailty status and geriatric syndromes (including history of falls in the previous 90 days, impaired cognition, dependence in basic and instrumental ADL, and bladder incontinence), only the FI had a significant association with polypharmacy.

Table 2 shows outcomes at discharge from the TCP according to polypharmacy status. The majority of patients continued living in the community $(85.6 \%), 12.4 \%$ were readmitted to hospital, $0.9 \%$ were discharged to residential aged care facilities (RACF), and $1.2 \%$ died. Patients in the polypharmacy and hyperpolypharmacy groups were more likely than the non-polypharmacy group to fail to improve in ADL and IADL and were more likely to fall over the duration of the TCP.

Multivariate models of functional outcomes (failure to improve ADL or IADL or falls over the TCP), with FI and polypharmacy groups as covariates, show that frailty status mediates the effects of polypharmacy. The odds ratios of ADL and IADL functional decline and falls for a 0.1 increase in FI are shown in Table 3.

Table 4 shows the most common drug categories by polypharmacy group. The most commonly used drugs were analgesics (56.8\%). Non-opioid drugs were prescribed more 
Table I Characteristics of patients on admission to the TCP according to polypharmacy status

\begin{tabular}{|c|c|c|c|c|c|}
\hline & $\begin{array}{l}\text { All } \\
n=347\end{array}$ & $\begin{array}{l}\text { Non-polypharmacy } \\
<5 \text { drugs } n=49 \\
(14.1 \%)\end{array}$ & $\begin{array}{l}\text { Polypharmacy } \\
\text { 5-9 drugs } \\
n=162(46.7 \%)\end{array}$ & $\begin{array}{l}\text { Hyperpolypharmacy } \\
\geq 10 \text { drugs } n=136 \\
(39.2 \%)\end{array}$ & $P$-value \\
\hline \multicolumn{6}{|l|}{ Demographics } \\
\hline Age, mean \pm SD & $78.9 \pm 8.8$ & $78.7 \pm 9.6$ & $78.5 \pm 8.6$ & $79.4 \pm 8.7$ & 0.696 \\
\hline Female & $228(65.7)$ & $30(6 \mid .2)$ & $104(64.2)$ & $94(69.1)$ & 0.521 \\
\hline \multicolumn{6}{|l|}{ Medications } \\
\hline Regular, mean \pm SD & $8.5 \pm 3.6$ & $2.8 \pm 1.2$ & $7.2 \pm 1.3$ & $12.2 \pm 2.0$ & $<0.001$ \\
\hline $\mathrm{PRN}$, mean $\pm \mathrm{SD}$ & $0.8 \pm 1.1$ & $0.9 \pm 1.1$ & $0.7 \pm 0.9$ & $0.9 \pm 1.2$ & $0.34 I$ \\
\hline \multicolumn{6}{|l|}{ Comorbidities } \\
\hline No of comorbidities, mean \pm SD & $6.0 \pm 3.0$ & $3.9 \pm 2.5$ & $5.8 \pm 2.7$ & $7.0 \pm 3.1$ & $<0.001$ \\
\hline Diabetes & $89(26.3)$ & $6(12.8)$ & $39(25.2)$ & $44(32.4)$ & 0.029 \\
\hline Coronary heart disease & $116(34.1)$ & $7(14.9)$ & $57(35.8)$ & $52(38.8)$ & 0.010 \\
\hline COPD & $44(13.1)$ & $2(4.3)$ & $15(9.7)$ & $27(20.1)$ & 0.006 \\
\hline Depression & $72(21.4)$ & $3(6.4)$ & $38(24.5)$ & $31(23.0)$ & 0.015 \\
\hline \multicolumn{6}{|l|}{ Symptoms } \\
\hline Pain - moderate/severe & $179(52.0)$ & $24(50.0)$ & $69(43.1)$ & $86(63.2)$ & 0.002 \\
\hline Dizziness & $84(24.5)$ & $8(16.7)$ & $30(18.9)$ & $46(33.8)$ & 0.005 \\
\hline Dyspnea & $132(38.3)$ & $9(18.8)$ & $62(38.5)$ & $61(44.9)$ & 0.006 \\
\hline Fatigue - moderate/severe & I 48 (42.9) & $19(40.4)$ & $65(40.1)$ & $64(47.1)$ & 0.452 \\
\hline Constipation & $65(18.8)$ & $7(14.6)$ & $28(17.4)$ & $30(22.1)$ & 0.425 \\
\hline \multicolumn{6}{|c|}{ Geriatric syndromes and frailty status } \\
\hline Falls in previous 90 days & $201(58.6)$ & $25(52.1)$ & $97(61.0)$ & $79(58.1)$ & 0.539 \\
\hline Cognition impaired ${ }^{\mathrm{a}}$ & $102(29.8)$ & $14(29.2)$ & $54(34.2)$ & $34(25.0)$ & 0.228 \\
\hline ADL scale, ${ }^{\mathrm{b}}$ median (IQR) & $3(I-6)$ & $3(0-7.5)$ & $3(I-6)$ & $4(I-6)$ & 0.588 \\
\hline IADL scale, ${ }^{c}$ median (IQR) & $25(|9-3|)$ & $25.5(19.25-29.75)$ & $25(18.5-32)$ & $26(\mid 9-31)$ & 0.813 \\
\hline Daily bladder incontinence & $46(13.3)$ & $7(14.3)$ & $20(12.3)$ & $19(14.0)$ & 0.895 \\
\hline Frailty index, mean \pm SD & $0.30 \pm 0.12$ & $0.25 \pm 0.10$ & $0.30 \pm 0.11$ & $0.33 \pm 0.11$ & $<0.001$ \\
\hline
\end{tabular}

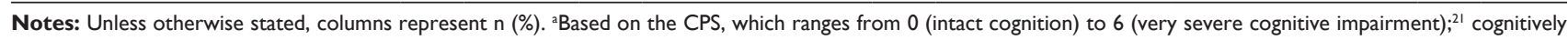
impaired patients were defined as CPS scores $\geq 2$, corresponding to a mean Mini Mental State Examination score of $<24$.' ${ }^{21}$ Based on ADL scale (long form), which assesses independence in seven ADL items (personal hygiene, dressing upper body and lower body, locomotion, toilet use, bed mobility, and eating). The scale has a range from 0 to 28 , with higher scores indicating greater dependence. ${ }^{17}$ CThe IADL scale summarizes the performance on seven IADL items (meal preparation, housework, finances, medication management, phone use, shopping, and transport). The scale has a range from 0 to 42 , with higher scores indicating greater dependence..$^{17}$

Abbreviations: ADL, activities of daily living; COPD, chronic obstructive pulmonary disease; CPS, cognitive performance scale; IADL, instrumental ADL; IQR, interquartile range; PRN, pro re nata; SD, standard deviation; TCP, Transition Care Program.

frequently than opioids ( $46.1 \%$ and $27.1 \%$, respectively). Anti-ulcer drugs (52.7\%), statins (44.1\%), aspirin, and anti-aggregates $(43.2 \%)$ followed. Cardiovascular drugs were also commonly used. Beta blockers and angiotensin converting enzyme inhibitors were each prescribed in about a third of patients, while diuretics, calcium channel blockers, and angiotensin receptor blockers were each prescribed in about a quarter of the patients. Vitamin D and analogues

Table 2 Outcomes at discharge from the TCP according to polypharmacy status

\begin{tabular}{|c|c|c|c|c|c|}
\hline & $\begin{array}{l}\text { All } \\
n=347\end{array}$ & $\begin{array}{l}\text { Non-polypharmacy } \\
<5 \text { drugs } n=49 \\
(14.1 \%)\end{array}$ & $\begin{array}{l}\text { Polypharmacy } \\
5-9 \text { drugs } \\
n=162(46.7 \%)\end{array}$ & $\begin{array}{l}\text { Hyperpolypharmacy } \\
\geq 10 \text { drugs } n=136 \\
(39.2 \%)\end{array}$ & $P$-value \\
\hline Discharge destination & & & & & 0.200 \\
\hline - Community & $297(85.6)$ & $44(89.8)$ & $139(85.8)$ & I I 4 (83.8) & \\
\hline - Hospital & $43(12.4)$ & $3(6.1)$ & $20(12.3)$ & $20(14.7)$ & \\
\hline- RACF & $3(0.9)$ & $2(4.1)$ & I (0.6) & $0(0.0)$ & \\
\hline - Died & $4(1.2)$ & $0(0.0)$ & $2(1.2)$ & $2(1.5)$ & \\
\hline Length of stay (days) median (IQR) & $54(37-73)$ & $57(38.5-80)$ & $54(38.75-69.25)$ & $48.5(31.25-73)$ & 0.199 \\
\hline Failure to improve in $\mathrm{ADL}^{\mathrm{a}}$ & $42(12.6)$ & $2(4 . I)$ & $15(9.8)$ & $25(18.9)$ & 0.011 \\
\hline Failure to improve in $\mathrm{IADL}^{\mathrm{b}}$ & $63(19.0)$ & $4(8.3)$ & $23(14.9)$ & $36(27.7)$ & 0.003 \\
\hline Falls while in the TCP & $48(15.3)$ & $2(4.5)$ & $30(20.4)$ & $16(13.0)$ & 0.023 \\
\hline
\end{tabular}


Table 3 Logistic regression modelling of functional outcomes at discharge from the TCP

\begin{tabular}{|c|c|c|c|}
\hline Covariates & $\begin{array}{l}\text { Failure to improve } \\
\text { ADL OR }(95 \% \mathrm{Cl})\end{array}$ & $\begin{array}{l}\text { Failure to improve } \\
\text { IADL OR }(95 \% \mathrm{CI})\end{array}$ & $\begin{array}{l}\text { Falls OR } \\
(95 \% \mathrm{Cl})\end{array}$ \\
\hline \multicolumn{4}{|l|}{ Medication use } \\
\hline - Non-polypharmacy & 1 & 1 & 1 \\
\hline - Polypharmacy & $2.22(0.48-10.16)$ & $1.68(0.55-5.19)$ & $4.69(1.06-20.68)^{*}$ \\
\hline - Hyperpolypharmacy & $4.33(0.97-19.42)$ & $3.42(1.13-10.38)^{*}$ & $2.34(0.50-10.84)$ \\
\hline Frailty index & $1.38(1.01-1.87)^{*}$ & $1.36(1.04-1.77)^{*}$ & $1.50(1.12-2.01)^{* *}$ \\
\hline
\end{tabular}

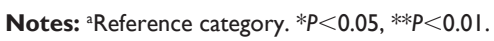

Abbreviations: $A D L$, activities of daily living; IADL, instrumental ADL; Cl, confidence interval; OR, odds ratio; TCP, Transition Care Program.

were prescribed in $27.1 \%$, while anti-resorptives and calcium were taken by $22.5 \%$ and $24.5 \%$, respectively. A high proportion was prescribed antidepressants (30.8\%) and laxatives (28\%). Only nine patients were on antipsychotics and four patients on anti-dementia drugs. In all but a few drug categories (anticoagulants, oral hypoglycemics, anti-emetics,
anti-Parkinson, antipsychotics, and anti-dementia drugs) the prevalence of each drug class increased significantly across the polypharmacy groups, with the hyperpolypharmacy group having the highest prevalence.

The number of TCP patients taking at least one PIM was $41(11.8 \%)$, with two persons taking two PIMs. Of

Table 4 Prevalence of drug use in TCP patients by medication class

\begin{tabular}{|c|c|c|c|c|}
\hline Drug & $\begin{array}{l}\text { All } \\
n=347\end{array}$ & $\begin{array}{l}\text { Non-polypharmacy } \\
<5 \text { drugs } n=49 \\
(14.1 \%)\end{array}$ & $\begin{array}{l}\text { Polypharmacy } \\
\text { 5-9 drugs } \\
n=162(46.7 \%)\end{array}$ & $\begin{array}{l}\text { Hyperpolypharmacy } \\
\geq 10 \text { drugs } n=136 \\
(39.2 \%)\end{array}$ \\
\hline Analgesics & $197(58.6)$ & $15(30.6)$ & $84(51.9)$ & $98(72.1)$ \\
\hline - Non-opioids & $160(46.1)$ & $9(18.4)$ & $73(45.1)$ & $78(57.4)$ \\
\hline - Opioids & $94(27.1)$ & $8(16.3)$ & $31(19.1)$ & $55(40.4)$ \\
\hline Antiulcer & $183(52.7)$ & $12(24.5)$ & $80(49.4)$ & $91(66.9)$ \\
\hline Statins & $153(44.1)$ & II (22.4) & $64(39.5)$ & $78(57.4)$ \\
\hline Aspirin and anti-aggregates & $150(43.2)$ & $9(18.4)$ & $64(39.5)$ & $77(56.6)$ \\
\hline Beta blockers & $119(34.3)$ & $7(14.3)$ & $53(32.7)$ & $59(43.4)$ \\
\hline Angiotensin converting enzyme inhibitors & $109(31.4)$ & $9(18.4)$ & $47(29.0)$ & $53(39.0)$ \\
\hline Antidepressants & $107(30.8)$ & I $(2.0)$ & $5 I(3 I .5)$ & $55(40.4)$ \\
\hline - Tricyclics & $33(9.5)$ & I (2.0) & $13(8.0)$ & $19(14.0)$ \\
\hline$-\mathrm{SSRIS}$ & $47(13.5)$ & $0(0.0)$ & $23(14.2)$ & $24(17.6)$ \\
\hline - MAO inhibitors & I $(0.3)$ & $0(0.0)$ & I $(0.6)$ & $0(0.0)$ \\
\hline - Other (eg, SNRIs) & $30(8.6)$ & $0(0.0)$ & $15(9.3)$ & I5 (I I.0) \\
\hline Laxatives & $97(28.0)$ & $6(12.2)$ & $32(19.8)$ & $59(43.4)$ \\
\hline Vitamin D and analogues & $94(27.1)$ & $3(6.1)$ & $4 I(25.3)$ & $50(36.8)$ \\
\hline Diuretics & $94(27.1)$ & $3(6.1)$ & $35(21.6)$ & $56(4 I .2)$ \\
\hline Calcium channel blockers & $90(25.90)$ & $3(6.1)$ & $39(24.1)$ & $48(35.3)$ \\
\hline Calcium & $85(24.5)$ & $3(6.1)$ & $36(22.2)$ & $46(33.8)$ \\
\hline Angiotensin receptor blockers & $78(22.5)$ & $2(4.1)$ & $42(25.9)$ & $34(25.0)$ \\
\hline Osteoporosis/anti-resorptives & $78(22.5)$ & $4(8.2)$ & $31(19.1)$ & $43(31.6)$ \\
\hline Anticoagulants & $59(17.0)$ & $7(\mid 4.3)$ & $32(19.8)$ & $20(14.7)$ \\
\hline - Heparin & $15(4.3)$ & $3(6.1)$ & $7(4.3)$ & $5(3.7)$ \\
\hline - Warfarin & $46(13.3)$ & $4(8.2)$ & $26(16.6)$ & $16(11.7)$ \\
\hline Oral hypoglycemics & $57(16.4)$ & $4(8.2)$ & $25(15.4)$ & $28(20.6)$ \\
\hline Eye medications & $50(14.4)$ & $2(4.1)$ & $17(10.5)$ & $31(22.8)$ \\
\hline Thyroid medications & $48(13.8)$ & $3(6.1)$ & $14(8.6)$ & $31(22.8)$ \\
\hline COPD/asthma medications & $48(13.8)$ & I (2.0) & $16(9.9)$ & $31(22.8)$ \\
\hline Corticosteroids & $46(13.3)$ & $\mathrm{I}(2.2)$ & $16(9.9)$ & $29(21.3)$ \\
\hline Benzodiazepines & $44(12.7)$ & $3(6.1)$ & $12(27.3)$ & $29(21.3)$ \\
\hline Antibacterials & $44(12.7)$ & I (2.0) & $18(11.1)$ & $25(18.4)$ \\
\hline Nitrates & $37(10.7)$ & $0(0.0)$ & $10(6.2)$ & 27 (19.9) \\
\hline Digoxin & $30(8.6)$ & I $(2.0)$ & $10(6.2)$ & $19(14.0)$ \\
\hline Insulin & $20(5.8)$ & $0(0.0)$ & $3(1.9)$ & 17 (12.5) \\
\hline Anti-emetics & 15 (4.3) & I (2.0) & $5(3.1)$ & $9(6.6)$ \\
\hline Anti-Parkinson & $12(3.5)$ & $2(4.1)$ & $4(2.5)$ & $6(4.4)$ \\
\hline Antipsychotics & $9(2.6)$ & I (2.0) & $5(3.1)$ & $3(2.2)$ \\
\hline Anti-dementia drugs & $4(1.2)$ & $0(0.0)$ & $3(1.9)$ & I (0.7) \\
\hline
\end{tabular}

Abbreviations: COPD, chronic obstructive pulmonary disease; MAO, monoamine oxidase; SNRI, serotonin norepinephrine reuptake inhibitor; SSRI, selective serotonin reuptake inhibitor; TCP, Transition Care Program. 
those taking at least one PIM, 2 (4.1\%) were in the nonpolypharmacy group; $17(10.5 \%)$ were in the polypharmacy group; and $22(16.2 \%)$ in the hyperpolypharmacy group. This distribution failed to reach statistical significance $(P=0.066$; Fisher's exact test). The commonest PIMs prescribed were tertiary tricyclic antidepressants $(9.5 \%)$, particularly amitriptyline. Digoxin at a dose of $>125 \mu \mathrm{g}$ was prescribed in less than $2 \%$ of patients. Dipyridamol, promethazine, glibenclamide, and oral estrogens were each prescribed in only one or two patients. None of the patients was prescribed potent non-steroidal anti-inflammatory drugs which increase the risk of gastrointestinal bleeding and peptic ulceration. There were no patients on barbiturates or the antiparkinsonian agent, benztropine.

\section{Discussion}

The findings of this study showed that polypharmacy was significantly associated with frailty and poor functional outcomes. However, multivariate models of functional outcomes (failure to improve ADL or IADL or falls over the TCP), with FI and polypharmacy groups as covariates, show that frailty status mediates the effects of polypharmacy. This accords with previous findings which indicate that older adults who are frail are more likely to be exposed to multiple medications associated with increases in number of comorbidities. Conversely, multiple medications may exacerbate frailty. ${ }^{24}$ While the association of polypharmacy with frailty and adverse outcomes has been shown in studies of community-dwelling older adults, ${ }^{22,24,28}$ there have been few studies which have shown this relationship in the post-acute care setting.

The majority of patients in our study $(86 \%)$ were prescribed five or more medications per day. The mean number of drugs of 8.5 is higher than that reported in other studies of nursing home patients, community-dwellers, and day hospital patients, which report values of 3.7-7.9.4,10,29-31 The definition of polypharmacy and inclusion of vitamins, minerals, and over-the-counter medications was variable in these other studies, making comparison difficult.

Similar to previous reports, ${ }^{23,32}$ prevalence of diabetes mellitus, coronary heart disease, COPD, and depression were lower in the non-polypharmacy group, as were symptoms of dizziness and dyspnea. In contrast to a previous study, ${ }^{23}$ measures of ADL, IADL, and cognition were not associated with polypharmacy at admission to the TCP. However, better functional outcomes in ADL and IADL were achieved with TCP rehabilitation for those on fewer medications. This was most likely because of their lower levels of frailty, which is a predictor of functional gain in rehabilitation patients. ${ }^{8}$ Those with fewer medications were less likely to fall over the duration of the TCP, which is consistent with studies showing a relationship between polypharmacy and risk of falls. ${ }^{33}$ A strong association between cognitive impairment and reduced rates of excessive polypharmacy has recently been described in nursing-home residents. ${ }^{23}$ In contrast, our study did not find such an association, most likely due to the small number of patients with severe cognitive impairment.

Analgesics were the most commonly prescribed class of medications, which may reflect the fact that the majority of patients had been hospitalized with fractures or for orthopedic procedures. While fractures were the commonest reason for hospitalization in patients admitted to the TCP, this was not mirrored by the use of anti-resorptives and vitamin $\mathrm{D}$ and analogues, which was lower than expected, given the importance of these medications in the prevention of osteoporotic fractures. ${ }^{34,35}$

Though analgesic use was high, no patients were prescribed potent non-steroidal anti-inflamatory drugs, which are listed as PIMs under the Beers Criteria, ${ }^{25}$ due to greater propensity for gastrointestinal side effects. The majority of PIMs that met Beers criteria were not prescribed for any of the patients in our study.

The difficulties comparing our study with other published polypharmacy studies, due to different patient selection and polypharmacy definitions, are acknowledged. Our study has prospectively collected data on functional outcomes in a cohort of patients often excluded from clinical studies - frail elderly patients residing in the community but meeting criteria for residential aged care. This is an important group of patients in which interventions can delay or avoid institutionalization. ${ }^{17}$ Considerations should be given to enabling regular medication reviews and rationalization in patients enrolled in community rehabilitation and Transition Care Programs, by encouraging regular pharmacist and medical input. These interventions have been shown to improve appropriate prescribing and reduce drug-related adverse events, though results on number of medications prescribed have been variable. , $^{6,36-39}$

The strengths of our study are that the cohort is characteristic of older people eligible for post-discharge home-based care and representative of TCP recipients in particular, having been recruited across multiple sites in both rural and metropolitan communities. Few studies have explored associations of polypharmacy with functional outcomes after a period of longitudinal follow up. A study limitation is that the medication lists were documented by the interRAI assessors who transcribed or photocopied the patients' drug charts from hospital discharge summaries. It is acknowledged that this method of 
collecting medication data is not the current gold standard. To achieve complete medication reconciliation, multiple sources of information (including patient interview, general practitioner's letter, and dispensing history from the pharmacy) should be accessed. A further limitation is that the indications for each medication prescribed could not be determined.

\section{Conclusion}

Polypharmacy is common in older patients discharged from hospital to home-based care. It is associated with frailty, falls, and poor functional outcomes. Efforts should be made to encourage regular medication reviews and rationalization of medications by pharmacists and geriatricians in these frail patients with reduced physiological reserves. Use of medications associated with functional decline such as benzodiazepines and anticholinergics as well as other PIMs should be minimized.

\section{Acknowledgments}

The project was supported by the Australian National Health and Medical Research Council Health Services Research Program Grant (ID 402791) on Transition Care: Innovation and Evidence. The funding source had no involvement in the study.

\section{Disclosure}

The authors declare that there are no conflicts of interest.

\section{References}

1. Hubbard RE, O'Mahony MS, Woodhouse KW. Medication prescribing in frail older people. Eur J Clin Pharmacol. 2013;69(3):319-326.

2. Slabaugh SL, Maio V, Templin M, Abouzaid S. Prevalence and risk of polypharmacy among the elderly in an outpatient setting: a retrospective cohort study in the Emilia-Romagna region, Italy. Drugs Aging. 2010; 27(12):1019-1028.

3. Haider SI, Johnell K, Thorslund M, Fastbom J. Analysis of the association between polypharmacy and socioeconomic position among elderly aged $\geq 77$ years in Sweden. Clin Ther. 2008;30(2):419-427.

4. Junius-Walker U, Theile G, Hummers-Pradier E. Prevalence and predictors of polypharmacy among older primary care patients in Germany. Fam Pract. 2007;24(1):14-19.

5. Harugeri A, Joseph J, Parthasarathi G, Ramesh M, Guido S. Potentially inappropriate medication use in elderly patients: a study of prevalence and predictors in two teaching hospitals. J Postgrad Med. 2010; 56(3):186-191.

6. Pitkala KH, Strandberg TE, Tilvis RS. Is it possible to reduce polypharmacy in the elderly? A randomised, controlled trial. Drugs Aging. 2001; 18(2):143-149.

7. Rockwood K, Mitnitski A. Frailty defined by deficit accumulation and geriatric medicine defined by frailty. Clin Geriatr Med. 2011;27(1): $17-26$.

8. Singh I, Gallacher J, Davis K, Johansen A, Eeles E, Hubbard RE. Predictors of adverse outcomes on an acute geriatric rehabilitation ward. Age Ageing. 2012;41(2):242-246.

9. Heuberger RA, Caudell K. Polypharmacy and nutritional status in older adults: a cross-sectional study. Drugs Aging. 2011;28(4):315-323.
10. Jyrkka J, Enlund H, Korhonen MJ, Sulkava R, Hartikainen S. Polypharmacy status as an indicator of mortality in an elderly population. Drugs Aging. 2009;26(12):1039-1048.

11. Lai SW, Liao KF, Liao CC, Muo CH, Liu CS, Sung FC. Polypharmacy correlates with increased risk for hip fracture in the elderly: a population-based study. Medicine (Baltimore). 2010;89(5): $295-299$.

12. Lin CF, Wang CY, Bai CH. Polypharmacy, aging and potential drugdrug interactions in outpatients in Taiwan: a retrospective computerized screening study. Drugs Aging. 2011;28(3):219-225.

13. Olivier P, Bertrand L, Tubery M, Lauque D, Montastruc JL, LapeyreMestre M. Hospitalizations because of adverse drug reactions in elderly patients admitted through the emergency department: a prospective survey. Drugs Aging. 2009;26(6):475-482.

14. Claxton AJ, Cramer J, Pierce C. A systematic review of the associations between dose regimens and medication compliance. Clin Ther. 2001; 23(8):1296-1310.

15. Schubert I, Kupper-Nybelen J, Ihle P, Thurmann P. Prescribing potentially inappropriate medication (PIM) in Germany's elderly as indicated by the PRISCUS list. An analysis based on regional claims data. Pharmacoepidemiol Drug Saf. 2013;22(7):719-727.

16. Department of Health and Ageing. Transition Care Program Guidelines. Canberra, ACT: Australian Government; 2011. Available from http:// www.health.gov.au/internet/main/publishing.nsf/content/ageingtransition-guidelines.htm. Accessed August 20, 2014.

17. Peel NM, Hubbard RE, Gray LC. Impact of post-acute transition care for frail older people: a prospective study. J Frailty Aging. 2013;2(3): $165-171$.

18. Gray LC, Berg K, Fries BE, et al. Sharing clinical information across care settings: the birth of an integrated assessment system. BMC Health Serv Res. 2009;9:71.

19. Hirdes J, Ljunggren G, Morris J, et al. Reliability of the interRAI suite of assessment instruments: a 12-country study of an integrated health information system. BMC Health Serv Res. 2008;8(1):277.

20. Lakhan P, Jones M, Wilson A, Courtney M, Hirdes J, Gray LC A prospective cohort study of geriatric syndromes among older medical patients admitted to acute care hospitals. J Am Geriatr Soc. 2011; 59(11):2001-2008.

21. Travers C, Byrne GJ, Pachana NA, Klein K, Gray L. Validation of the InterRAI Cognitive performance scale against independent clinical diagnosis and the mini-mental state examination in older hospitalized patients. J Nutr Health Aging. 2013;17(5): 435-439.

22. Gnjidic D, Hilmer SN, Blyth FM, et al. Polypharmacy cutoff and outcomes: five or more medicines were used to identify communitydwelling older men at risk of different adverse outcomes. J Clin Epidemiol. 2012;65(9):989-995.

23. Onder G, Liperoti R, Fialova D, et al. Polypharmacy in nursing home in Europe: results from the SHELTER study. J Gerontol A Biol Sci Med Sci. 2012;67(6):698-704

24. Gnjidic D, Hilmer SN, Blyth FM, et al. High-risk prescribing and incidence of frailty among older community-dwelling men. Clin Pharmacol Ther. 2012;91(3):521-528.

25. American Geriatrics Society Beers Criteria Update Expert Panel. American Geriatrics Society updated Beers Criteria for potentially inappropriate medication use in older adults. $J$ Am Geriatr Soc. 2012;60(4):616-631.

26. Searle SD, Mitnitski A, Gahbauer EA, Gill TM, Rockwood K. A standard procedure for creating a frailty index. BMC Geriatrics. $2008 ; 8: 24$

27. Rockwood K, Andrew M, Mitnitski A. A comparison of two approaches to measuring frailty in elderly people. J Gerontol A Biol Sci Med Sci. 2007;62(7):738-743.

28. Crentsil V, Ricks MO, Xue Q-L, Fried LP. A pharmacoepidemiologic study of community-dwelling, disabled older women: factors associated with medication use. Am J Geriatr Pharmacother. 2010;8(3): 215-224. 
29. Frankfort SV, Tulner LR, van Campen JP, Koks CH, Beijnen JH. Evaluation of pharmacotherapy in geriatric patients after performing complete geriatric assessment at a diagnostic day clinic. Clin Drug Investig. 2006;26(3):169-174.

30. Hosia-Randell HM, Muurinen SM, Pitkala KH. Exposure to potentially inappropriate drugs and drug-drug interactions in elderly nursing home residents in Helsinki, Finland: a cross-sectional study. Drugs Aging. 2008;25(8):683-692.

31. Johnell K, Klarin I. The relationship between number of drugs and potential drug-drug interactions in the elderly: a study of over 600,000 elderly patients from the Swedish Prescribed Drug Register. Drug Safety. 2007;30(10):911-918.

32. Jyrkka J, Enlund H, Korhonen MJ, Sulkava R, Hartikainen S. Patterns of drug use and factors associated with polypharmacy and excessive polypharmacy in elderly persons: results of the Kuopio 75+ study: a cross-sectional analysis. Drugs Aging. 2009;26(6):493-503.

33. Boyle N, Naganathan V, Cumming RG. Medication and falls: risk and optimization. Clin Geriatr Med. 2010;26(4):583-605.

34. American Geriatrics Society Workgroup on Vitamin D Supplementation for Older Adults. Recommendations abstracted from the American Geriatrics Society Consensus Statement on Vitamin D for Prevention of Falls and Their Consequences. J Am Geriatr Soc. 2014;62(1):147-152.
35. Bischoff-Ferrari HA, Staehelin HB. Importance of vitamin D and calcium at older age. Int J Vitam Nutr Res. 2008;78(6):286-292.

36. Lampela P, Hartikainen S, Lavikainen P, Sulkava R, Huupponen R. Effects of medication assessment as part of a comprehensive geriatric assessment on drug use over a 1-year period: a population-based intervention study. Drugs Aging. 2010;27(6):507-521.

37. Rollason V, Vogt N. Reduction of polypharmacy in the elderly: a systematic review of the role of the pharmacist. Drugs Aging. 2003; 20(11):817-832.

38. Vinks TH, Egberts TC, de Lange TM, de Koning FH. Pharmacist-based medication review reduces potential drug-related problems in the elderly: the SMOG controlled trial. Drugs Aging. 2009;26(2):123-133.

39. Sergi G, De Rui M, Sarti S, Manzato E. Polypharmacy in the elderly: can comprehensive geriatric assessment reduce inappropriate medication use? Drugs Aging. 2011;28(7):509-518. 


\section{Supplementary material}

Table SI Potentially inappropriate medications Beers Criteria 2012

\begin{tabular}{|c|c|c|}
\hline Potentially inappropriate medications & $\begin{array}{l}\text { ATC code for drug } \\
\text { as a single agent }\end{array}$ & $\begin{array}{l}\text { ATC code } \\
\text { in combina } \\
\text { other agen }\end{array}$ \\
\hline \multicolumn{3}{|l|}{ Anticholinergics } \\
\hline \multicolumn{3}{|l|}{ Antihistamines } \\
\hline \multicolumn{3}{|c|}{ (as single agent or as part of combination products) } \\
\hline Brompheniramine & $\mathrm{R} 06 \mathrm{AB} 0 \mathrm{I}$ & R06AB5I \\
\hline Carbinoxamine & R06AA08 & \\
\hline Chlorpheniramine & R06AB04 & R06AB54 \\
\hline Clemastine & R06AA04 & R06AA54 \\
\hline Cyproheptadine & $\mathrm{R} 06 \mathrm{~A} \times 02$ & \\
\hline Dexbrompheniramine & R06AB06 & R06AB56 \\
\hline Dexchlorpheniramine & $\mathrm{R} 06 \mathrm{AB} 02$ & R06AB52 \\
\hline Diphenhydramine (oral) & R06AA02 & R06AA52 \\
\hline Doxylamine & R06AA09 & R06AA59 \\
\hline Hydroxyzine & N05BB0I & N05BB5I \\
\hline Promethazine & R06AD02 & R06AD52 \\
\hline Triprolidine & R06AX07 & \\
\hline \multicolumn{3}{|l|}{ Antiparkinson agents } \\
\hline Benztropine (oral) & N04AC0I & \\
\hline Trihexyphenidyl & N04AA0I & \\
\hline \multicolumn{3}{|l|}{ Antithrombotics } \\
\hline Dipyridamole, oral short acting* & $\mathrm{B} 0 \mathrm{IAC} 07$ & \\
\hline \multicolumn{3}{|c|}{ (does not apply to extended release combination with aspirin) } \\
\hline Ticlopidine* & B0IAC05 & \\
\hline \multicolumn{3}{|l|}{ Anti-arrhythmics } \\
\hline Digoxin $>0.125 \mathrm{mg} / \mathrm{d}$ & C0IAA05 & \\
\hline \multicolumn{3}{|l|}{ Tertiary TCAs, alone or in combination } \\
\hline Amitriptyline & N06AA09 & N06CA0I \\
\hline Chlordiazepoxide-amitriptyline & & N06CAOI \\
\hline Clomipramine & N06AA04 & \\
\hline Doxepin $>6 \mathrm{mg} / \mathrm{d}$ & N06AAI 2 & \\
\hline Imipramine & N06AA02 & N06AA03 \\
\hline Perphenazine-amitriptyline & & N06CA0I \\
\hline Trimipramine & N06AA06 & \\
\hline \multicolumn{3}{|l|}{ Barbiturates } \\
\hline Amobarbital* & N05CA02 & \\
\hline Butabarbital* & None & \\
\hline Butalbital & None & \\
\hline Mephobarbital* & N03AA0I & \\
\hline Pentobarbital* & N05CA0I & \\
\hline Phenobarbital & N03AA02 & \\
\hline Secobarbital* & N05CA06 & \\
\hline Meprobamate & N05BC0I & N05BC5I \\
\hline \multicolumn{3}{|l|}{ Sulfonylureas, long duration } \\
\hline Chlorpropamide & A $10 \mathrm{BB} 02$ & \\
\hline Glyburide (glibenclamide) & AIOBBOI & \\
\hline \multicolumn{3}{|l|}{ Analgesics } \\
\hline Meperidine & $\mathrm{N} 02 \mathrm{AB} 02$ & \\
\hline Indomethacin & MOIABOI & \\
\hline Ketorolac & MOIABI5 & \\
\hline Pentazocine* & N02AD0I & \\
\hline \multicolumn{3}{|l|}{ Antipsychotics } \\
\hline Thioridazine & N05AC02 & \\
\hline Mesoridazine & N05AC03 & \\
\hline
\end{tabular}


Table SI (Continued)

\begin{tabular}{|c|c|c|}
\hline Potentially inappropriate medications & $\begin{array}{l}\text { ATC code for drug } \\
\text { as a single agent }\end{array}$ & $\begin{array}{l}\text { ATC code(s) for drug } \\
\text { in combination with } \\
\text { other agents }\end{array}$ \\
\hline Meprobamate & N05BC0I & N05BC5I \\
\hline Ergot mesylates* & C04AE5I & \\
\hline \multicolumn{3}{|l|}{ Isoxsuprine* } \\
\hline \multicolumn{3}{|l|}{ Endocrine } \\
\hline Estrogens with or without progestins (oral and patch) & G03 & \\
\hline \multirow[t]{2}{*}{ Megestrol } & G03AC05 G03DB02 L02AB0I & G03FA08 G03FB04 \\
\hline & & G03AA04 G03AB0I \\
\hline \multicolumn{3}{|l|}{ Skeletal muscle relaxants } \\
\hline Carisoprodol & M03BA02 & \\
\hline Chlorzoxazone & М03ВВ03 & \\
\hline Cyclobenzaprine & М03ВХ08 & \\
\hline Metaxalone & M03BX08 & \\
\hline Methocarbamol & М03BA03 & \\
\hline Orphenadrine & N04AB02 & M03BC0I M03BC5I \\
\hline
\end{tabular}

Note: *Infrequently used drugs.

Abbreviations: ATC, anatomical therapeutic chemical; TCA, tricyclic antidepressants.

\section{Publish your work in this journal}

Clinical Interventions in Aging is an international, peer-reviewed journal focusing on evidence-based reports on the value or lack thereof of treatments intended to prevent or delay the onset of maladaptive correlates of aging in human beings. This journal is indexed on PubMed Central, MedLine,
CAS, Scopus and the Elsevier Bibliographic databases. The manuscript management system is completely online and includes a very quick and fair peer-review system, which is all easy to use. Visit http://www.dovepress. com/testimonials.php to read real quotes from published authors. 